\title{
DESIGN, CULTURA MATERIAL, ARTESANATO E MEMÓRIA: A METODOLOGIA DO DESIGN PARTICIPATIVO NO MUSEU DE FAVELA DO RIO DE JANEIRO
}

\author{
Davison Coutinho \\ PUC-Rio \\ infprofessor@gmail.com \\ Jorge Langone \\ PUC-Rio \\ jorgelangone@gmail.com \\ Nilton G. Gamba Junior \\ PUC-Rio \\ gambajunior@gmail.com
}

Resumo: Este artigo apresenta um resumo da dissertação de mestrado Design, Cultura Material, Artesanato e Memória defendida no Programa de Pós-Graduação em Design da PUC-Rio em abril de 2016. O objetivo geral da pesquisa é de criar uma metodologia, por meio da pesquisa-intervenção, que capacite às artesãs da Rede de artesanato do Museu de Favela do Cantagalo, Pavão e Pavãozinho para análise da imagem no contexto do desenvolvimento de seus produtos. A pesquisa realizou oficinas colaborativas para criação da exposição do prêmio Mulheres Guerreiras com as artesãs do MUF realizando um diálogo com os conceitos de Pier Paolo Pasolini em conjunção com a metodologia do Design Participativo e os conceitos de Memória Individual e Coletiva de Maurice Halbwachs. As etapas do processo foram construídas pelos moradores e pesquisadores envolvidos através das aulas expositivas e das oficinas práticas. Os dados revelaram que a participação ativa dos moradores para construção de uma linguagem própria os transforma em potenciais multiplicadores dos fazeres locais, ressaltando os seus saberes da cultura material da comunidade envolvida

Palavras-chave: Memória, Design Participativo, Favela, Artesanato

Asbtract: This article presents a summary of the dissertation Design, Material Culture, Crafts and memory held in the Graduate Program in Design at PUC-RIo in April 2016. The overall objective of the research is to create a methodology through research -intervention, which enables the artisans of Favela Museum of craft Network Cantagalo, Pavão and Pavãozinho for image analysis in the development of its products. The research conducted collaborative workshops for creating the exhibition Women Warrior Award with the artisans of the MUF conducting a dialogue with the concepts of Pier Paolo Pasolini in conjunction with the methodology of Participatory Design and the concepts of individual and 
Collective Memory Maurice Halbwachs. All process steps were built by residents and researchers involved through lectures and practical workshops. The data revealed that the active participation of residents to build a language turns them into potential multipliers of local doings, emphasizing their knowledge of the community's material culture involved.

Keywords: Memory Participatory Design, Favela, handicraft

\section{INTRODUÇÃO}

A aspiração de uma pesquisa acadêmica sobre a produção cultural dos moradores de favelas surgiu no projeto final da Graduação em Design na PUC-Rio: O Inverso dos Estereótipos: a vivência do cotidiano social em uma comunidade chamada Rocinha do então estudante de Design que objetivou o registro, em um livro ilustrado e fotográfico: Um Olhar Sobre a Produção Cultural na Rocinha, que mostra um pouco da cultura que circula na Rocinha e os aspectos do cotidiano dos moradores da comunidade. $\mathrm{O}$ objetivo foi mostrar à sociedade valores e aspectos culturais que ainda não tem visibilidade, mas são produzidos em um contexto de multiplicidade de experiências de cidadania e produção cultural.

A possibilidade desta pesquisa foi devido à parceria do Museu de Favela do Cantagalo, Pavão e Pavãozinho - MUF com o Núcleo Interdisciplinar de Memória, Subjetividade e Cultura da PUC-Rio - NIMESC/PUC-Rio. O NIMESC é um grupo de pesquisa interdepartamental do Laboratório de Design de Histórias do departamento de Design da PUC-Rio - LADEH com o laboratório de Psicologia da PUC-Rio.

A natureza do tema em foco é a contribuição do Design como veículo de transformação dos processos de materialização da memória de um grupo de artesãs da Rede MUF do Museu de Favela do Rio de Janeiro - MUF, por meio da capacitação visual dos fazeres locais das comunidades do Cantagalo, Pavão e Pavãozinho. Para tanto, para uma reflexão teórica, a pesquisa se apoia nos conceitos de de Linguagem Pedagógica das Coisas e Cultura Material do autor Pier Paolo Pasolini em conjunto com os conceitos de Memória Individual e Memória Coletiva do autor Maurice Halbwachs. A pesquisa utiliza-se de depoimentos e histórias de vida de mulheres, captados pela equipe de psicologia do NIMESC, para o projeto Mulheres Guerreiras, que será apresentado.

A pesquisa contribui para uma melhor aproximação do design com o artesanato e recuperação da memória das comunidades envolvidas. O projeto colabora para interface da área do Design validando que o mesmo pode contribuir socialmente para o desenvolvimento de pessoas e locais.

O objetivo geral é criar uma metodologia, por meio da pesquisa-intervenção, que capacite às artesãs da Rede MUF de artesanato para análise da imagem no contexto do desenvolvimento de seus produtos visando à sua integração no Museu de Favelas do Cantagalo, Pavão e Pavãozinho. O produto inicial, nesse trabalho, é a Exposição do Prêmio Mulheres Guerreiras. 


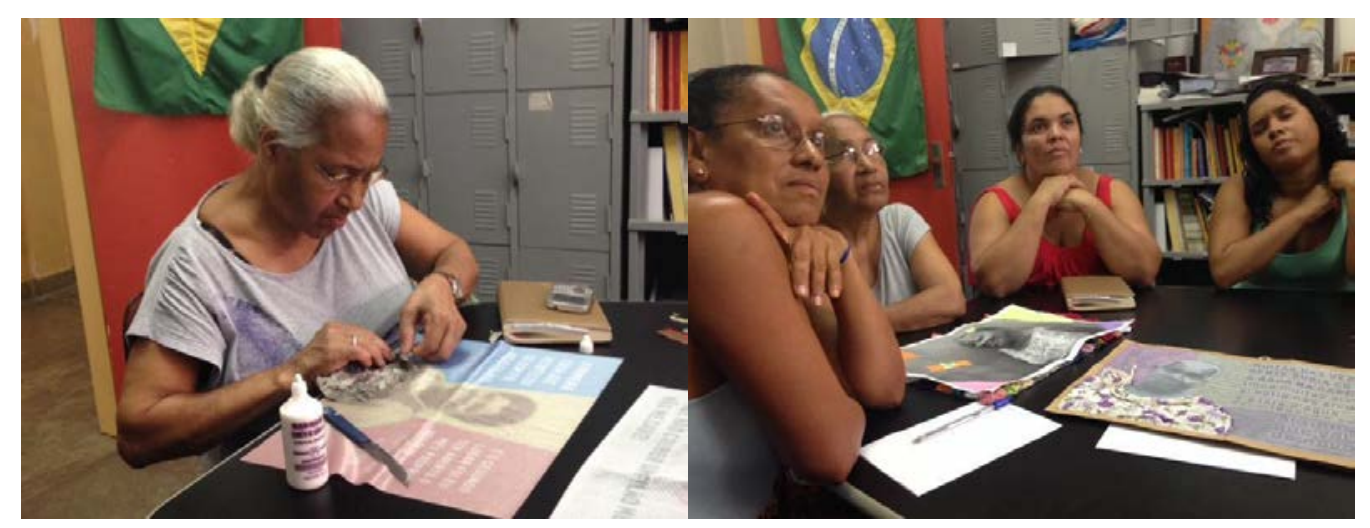

Figuras 1 e 2: "Oficinas com as artesãs do Museu de Favela" Elaborado pelo autor, com base na pesquisa realizada

\section{O PARCEIRO DA PESQUISA: MUSEU DE FAVELA - PRÊMIO MULHERES GUERREIRAS}

A ONG Museu de Favela - MUF é uma organização não governamental de caráter comunitário, formada por moradores das comunidades do Cantagalo, Pavão e Pavãozinho no Rio de Janeiro. A missão do MUF é preservar a memória da comunidade, promovendo a conexão entre os moradores e a cultura local. O museu apresenta diversas ações: Circuito Casas-tela, trilha ecológica e o Prêmio Mulheres Guerreiras. Esta última ação foi o objeto de estudo da pesquisa e será apresentada neste artigo.

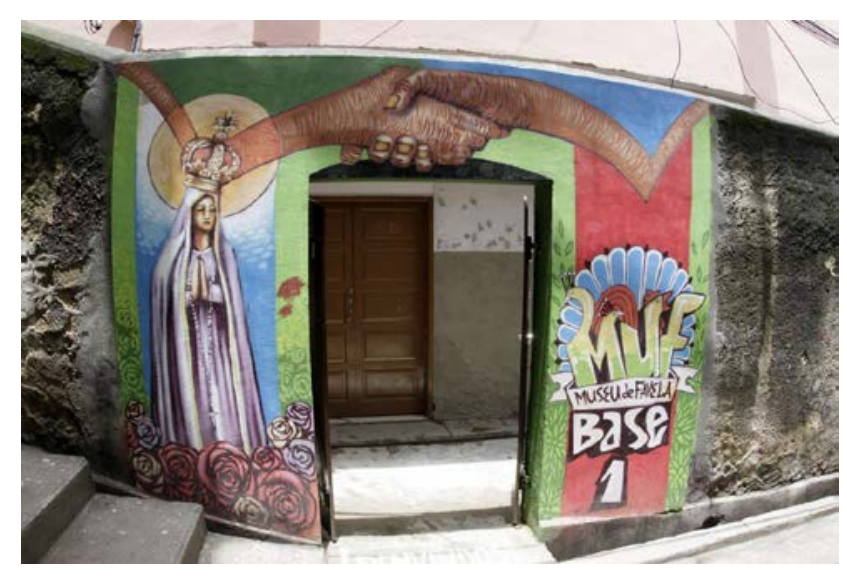

Figura 3: "Entrada do Museu MUF"- Cris Isidoro

O prêmio Mulheres Guerreiras faz parte do calendário de eventos culturais do Museu de Favela. O prêmio tem como intento homenagear, por meio de uma exposição, mulheres, moradoras das favelas do Cantagalo, Pavão e Pavãozinho que tenham histórias de vidas marcadas pela luta, força e coragem. O prêmio contempla mulheres que se orgulham da própria trajetória de vida que enfrentaram as dificuldades em nome da família e do bem-estar coletivo da comunidade

Os problemas que essa pesquisa busca resolver são:

- Como o desenvolvimento de uma linguagem visual própria de identidade local auxilia na integração da Rede MUF de artesanato com o Museu de Favelas?

- Como dar visibilidade ao processo de análise da imagem e criar um processo de capacitação das artesãs? 
- Como aplicar os resultados em um projeto em parceria como exercício de uma linguagem própria?

O objetivo das oficinas de capacitação no MUF era a intervenção da metodologia do design em duas ações do museu: O Prêmio Mulheres Guerreiras e o Circuito Casas Tela. As ações tinham questões distintas: a primeira se tratava da produção de um material para exposição e circulação do Prêmio Mulheres Guerreiras. A segunda ação era a recuperação de signos locais para a criação de uma linha de produtos singulares a serem produzidos pelas artesãs. Nesta pesquisa, abrangemos o prêmio Mulheres Guerreiras que serviu como uma das bases conceituais para a segunda ação no museu, desenvolvida na pesquisa de doutorado, em andamento, do Professor Jorge Langone, também pesquisador, professor do Departamento de Artes e Design da PUC-Rio.

\title{
3. PASOLINI DIÁLOGOS COM A FAVELA E A LINGUAGEM PEDAGÓGICA DAS COISAS
}

\author{
A educação que um menino recebe dos objetos, das coisas, da \\ realidade física - em outras palavras, dos fenômenos materiais da sua \\ condição social-, torna o corporalmente aquilo que é e será por toda a vida. 0 \\ que é educada é a sua carne, como forma do seu espírito (PASOLINI, 1990, p. \\ 127).
}

A obra de Pasolini é múltipla. Inclui projetos de diversas áreas tais como: cinema, poesia, desenho e teatro, além de estudos sobre a linguagem. Sua produção teórica vai de ensaios até a uma conceituação sobre o que ele chama de Semiologia da Realidade. A relevância de sua obra para a área do Design é trabalhar com os conceitos de Pedagogia Material e Linguagem Pedagógica das Coisas, que formula como um enfrentamento da linguagem visual e suas especificidades, em sua cultura, se comparada, à linguagem textual.

Outra afinidade da pesquisa com o autor é o campo de observação de Pasolini, como descrito anteriormente, se dedica a observação dos campesinos romanos e de populações subproletariadas que são marginalizadas pelo novo contexto socioeconômico. Além de falar de um contexto parecido com o momento histórico de consolidação das favelas no Brasil, Pasolini vai ser visionário ao defender que esse processo seria acelerado nas próximas décadas apontando assim, a importância de uma leitura da materialidade que o fundamenta, o contrapõe ou gera novas alternativas. Para entender o mito criado para o favelado, a priori, é fundamental entender sua linguagem, material e desarticulada sob o ponto de vista da argumentação meramente retórica. O autor apresenta uma linguagem menos articulada que a linguagem textual, e por isso, menos passível de argumentações, é a Linguagem Pedagógica das Coisas.

Em um ensaio, em forma de carta que Pasolini (1990) simula escrever ao aluno Genariello (personagem fictício) intitulada de Genariello: A linguagem Pedagógica das Coisas, ele afirma que as primeiras lembranças da vida são visuais e que todos os indivíduos têm na mente a primeira ou uma das primeiras imagens da vida. Segundo o autor, os objetos e os lugares nas suas primeiras imagens condensavam, em torno de si, um mundo de memórias e, principalmente, comunicavam. Era o discurso das coisas.

Pasolini conceitua um diálogo com os objetos, extraindo da própria materialidade e linguagem das coisas, a realidade, tal como ela é, a partir de uma 
experiência vivida, concreta e corporal. Sendo uma leitura diferente da verbal que para ele está carregada de artificialidade. Neste sentido, para Pasolini olhar as coisas permite conhecer a verdade que se encontra nos objetos, nas pessoas, nas paisagens de forma direta, e inarticulada.

Para Pasolini as imagens transmitem a diversidade de significados dos espaços, transmitindo sensações e interpretações que fogem aos limites da linguagem verbal, se somam a ela e ensinam ao leitor um entendimento de uma cultura como um todo: “(...) Imagem é um signo e, para sermos exatos, um signo linguístico. Portanto, se é um signo linguístico, comunica ou expressa alguma coisa” (PASOLINI, 1990, p.125).

Como Pasolini afirma cada indivíduo tem uma forma diferente de perceber as coisas e lugares, que depende de seu tempo, condição social, bem como seu grau de relação com esta ambiência. Esta relação pode ser uma grande diferença entre a pessoa que apenas conhece a favela através da mídia televisiva e filmes e da pessoa que convive ou conhece de perto aquela realidade. Sem a apresentação de outros aspectos que contemplem a realidade de vida na favela não se ampliarão os olhares sobre a cidade nem se legitimarão as diferentes concepções entre os grupos.

\section{MEMÓRIA COLETIVA, INDIVIDUAL E CONSTRUÇÃO DA IDENTIDADE}

Halbwachs (2006) afirma que a recordação e lembranças não podem ser percebidas de maneira individuais, mas como suporte em todo o contexto social que o indivíduo está inserido. Para o autor o indivíduo que lembra é um indivíduo que está inserido em um grupo social.

A partir dos estudos de Halbwachs (2006), a memória passa a ser refletida em uma dimensão que transpassa o âmbito individual, afirmando que as memórias de um indivíduo não são só suas e que nenhuma memória pode existir separada da sociedade. O autor defende que as memórias são formações dos grupos sociais. Os grupos são os que destinam o que é memorável e os lugares onde essa memória será guardada.

De acordo com Halbwachs (2006) a Memória Individual existe, mas sempre a partir de uma memória de um grupo, ou seja, de uma memória coletiva. Ao fazer parte de um grupo social e partilhar coisas seria irrefutável não ser social. $\mathrm{O}$ autor descortina a memória, em um fenômeno coletivo e social: "Um homem que se lembra sozinho do que os outros não se lembram é como alguém que enxerga o que os outros não veem" (HALBWACHS, 2006, p.23).

A memória coletiva abrange as memórias individuais, quando acontece de determinadas lembranças individuais surgirem, estas mudam de aspecto na medida em que "são substituídas em um conjunto que não é mais uma consciência pessoal" (HALBWACHS, 2006, p. 72). Na favela, a chegada de diferentes indivíduos já, com suas memórias e uma história local se somam em ambiente onde o individual e o coletivo se integram de forma própria. A memória da favela, então, não é separada da memória da cidade como um todo, por isso, estereótipos e preconceitos vão fazer parte disso. E, muitas vezes, a imagem externa, desse mosaico da favela, vai ser uma imagem gravada na memória coletiva de ambos os grupos - quem mora no asfalto e quem vem de lá para sua casa na favela. 
É importante que as histórias e memórias dos moradores de favela sejam narradas para que não sejam esquecidas, para isso é preciso que sejam repassadas entre as gerações. Virar história. Virar uma memória contada por quem, de fato, viveu os acontecimentos de um grupo quando tem o papel de questionar a memória histórica criada como versão única, verdadeira e universal dos acontecimentos. Assim, a função da memória social é de complementar a memória histórica, a fim de chegar mais próximo de uma verdade e, desta forma, oferecer uma nova história das favelas. A memória

\section{A METODOLOGIA DO DESIGN PARTICIPATIVO: AS OFICINAS COLABORATIVAS PARA CRIAÇÃO DA EXPOSIÇÃO MULHERES GUERREIRAS}

O Design Participativo (DP) para Fabiarz e Ripper (2011) é uma relação entre os sujeitos: o designer com as suas habilidades e o parceiro com suas práticas, experiências e lacunas para o desenvolvimento de um projeto por meio da troca de saberes entre eles. Desenvolver tal metodologia é construir por meio da partilha, da troca, permitindo ir de encontro do outro. A relevância da pesquisa participativa centra-se na pesquisa com as comunidades envolvidas o que difere da pesquisa para a comunidade feita como encomenda como se a mesma fosse um cliente que contrata um serviço. Nesta abordagem a participação do parceiro no desenvolvimento do projeto é além de uma ação consultiva. No DP o usuário participa ativamente em todas as fases do processo, trabalhando como um co-criador das soluções elaboradas (SANTA-ROSA \& MORAES, 2012).

A relevância da pesquisa participativa centra-se na pesquisa "com" as comunidades envolvidas, o que difere da pesquisa "para" a comunidade. A pesquisa em questão objetivou, portanto, a geração de um conhecimento, caracterizado pela integração do saber local da comunidade com o conhecimento científico, resultando numa construção de conhecimento social.

\subsection{Os conceitos de representação da imagem da favela: Cheio, Vazio, Figurativo e Abstrato}

Nas conversas iniciais com os moradores e responsáveis pelo MUF, na escuta dos registros das memórias do prêmio das Mulheres Guerreiras 2013 e na bibliografia pesquisada sobre a favela foi possível identificar as categorias sígnicas que representariam a multiplicidade favela.

Segundo Athayde e Meirelles (2014), a relação do morador com a favela, traduz o sentimento dele para conquistar o seu espaço, o que consideram como "muito lugar" (p. 153), pois normalmente a casa na favela é construída com suor por seus moradores, em lugares de difícil acesso. Os autores observam que as construções ordenadas das cidades, como conjuntos habitacionais e apartamentos apresentam formas repetitivas e não representam externamente os seus moradores, não apresentam nada de particular de quem ali reside, são padronizadas: "Existe um 'deslugar' quando as pessoas estão alienadas do espaço, quando não veem nele nada de particular, quando o verbo " estar" inspira o tédio" (ATHAYDE; MEIRELLES, 2014, p. 153). O que para esses autores dificilmente ativa a memória e que mesmo sendo um lugar limpo, correto e legalizado não tem uma relação de pertencimento com o morador, como acontece na favela. Esse "deslugar", segundo os autores, é o inverso 
do que acontece com as construções da favela que revela seu conjunto de identidade em seu desenho e forma.

Com base nas seguintes definições sobre a favela, elencou-se alguns conceitos principais que seriam trabalhados nas oficinas com as artesãs que representam essa multiplicidade de saberes e fazeres da favela, são eles: Figurativo; Abstrato; Cheio e Vazio. O Cheio e o Vazio para abordar dois aspectos de vista de uma favela.

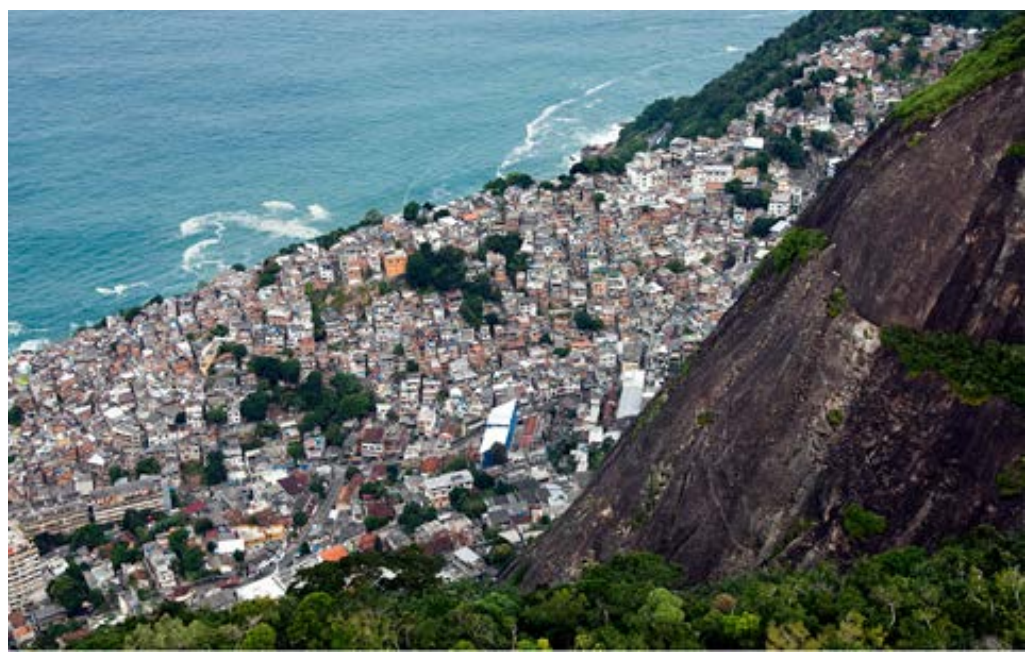

Figura 4: “Imagem signo da favela"

Elaborado pelo autor, com base na pesquisa realizada

A imagem uniforme vazia de elementos do céu ou do mar. A imagem do excesso no mosaico de casas. A ideia de figuração e abstração vem devido ao distanciamento desse ponto de vista da paisagem. Somem imagens não figurativas, como caixas de água e escadas e aproxima-se mais da abstração.

\subsection{As oficinas de materialização de memórias para exposição Mulheres}

\section{Guerreiras}

Pasolini (1990) ao mencionar a Linguagem Pedagógica das Coisas afirma que as "coisas" ensinam e revelam a cultura e o lugar que o indivíduo ocupa na classe social. Daí a importância de trabalhar com a materialização das memórias das mulheres guerreiras por meio do artesanato, técnica comum e já difundida nas comunidades envolvidas, para que as memórias que fazem parte da história da cidade sejam reveladas.

As oficinas com as artesãs no MUF se dividiram em dezessete encontros que podem ser subdivididos em oito etapas: a) introdução às categorias de representação da imagem; b) colocando os conceitos em prática; c) prototipagem; d) reapresentação dos conceitos de representação da imagem da favela; e) materializando histórias em imagens; f) mutirão de criação entre artesãs e pesquisadores; g) entrega da exposição ao MUF; h) lançamento da exposição com cortejo e i) Entrevista com as artesãs participantes. Destacamos neste artigo etapas da metodologia que evidenciam de maneira exemplar a relação direta com a obra de Pasolini e com a metodologia do Design Participativo. Selecionamos as etapas A, E, F que serão aqui retomadas.

A etapa A: Introdução às categorias de representação da imagem tinha como objetivo principal fazer com que as artesãs reconhecessem a partir de imagens da 
comunidade quais elementos que fazem parte do universo da favela poderiam ser utilizados no processo de criação do artesanato. A partir de exercícios dos conceitos abordados de Figurativo, Abstrato, Cheio e Vazio as artesãs tiveram a possibilidade de aprender sobre os conceitos. Em seguida, foi proposto um exercício para identificar em imagens da comunidade onde estes conceitos se apresentavam.

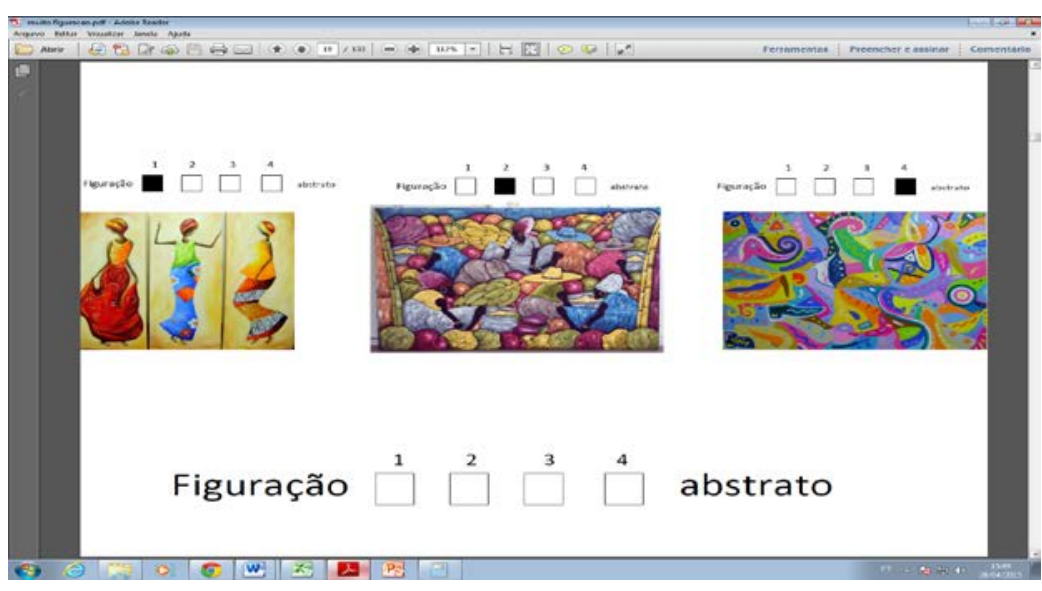

Figura 5 - "apresentação dos conceitos etapa A".

Elaborado pelos autores.

Em seguida, foram expostas imagens de produtos artesanais com os elementos conceituais apresentados até chegar à imagem signo da favela na qual as moradoras puderam observar a aplicação de tais conceitos.

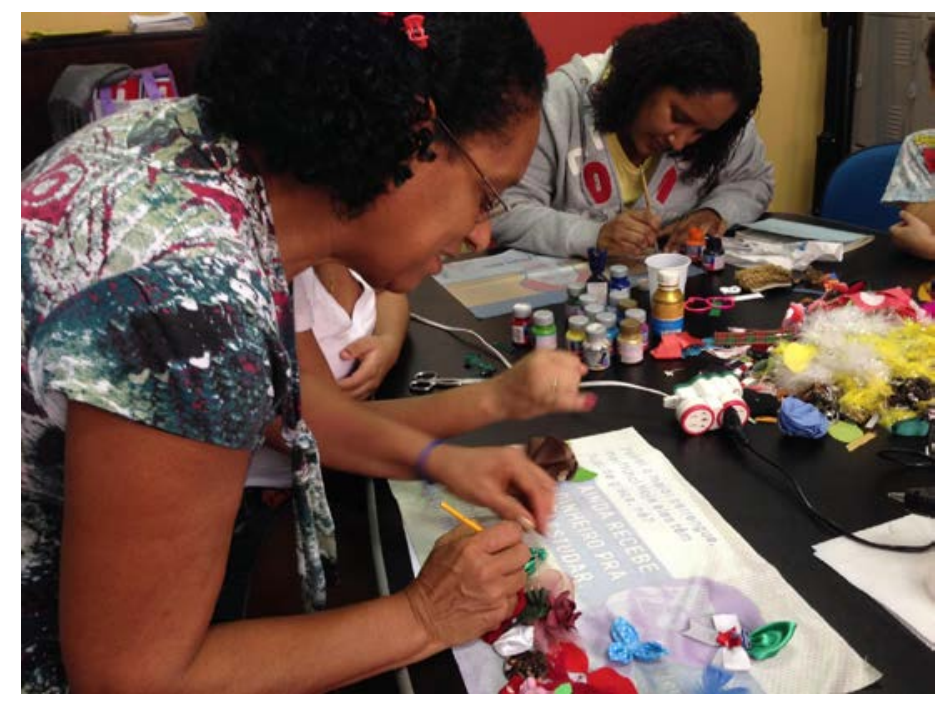

Figura: “Artesãs realizando exercício"

Elaborado pelo autor, com base na pesquisa realizada

Como Pasolini (1990) afirma o discurso das coisas é incontestável. As coisas comunicam e ensinam sobre o universo ao qual o indivíduo pertence. Desta forma, a etapa E: das oficinas que materializa as memórias em imagens traduz a evocação das lembranças de Pasolini sobre a cortina branca que traduzia todo o universo burguês que ele fazia parte. Nesta etapa, pesquisadores e artesãs fizeram a leitura dos depoimentos das treze mulheres guerreiras selecionadas e selecionaram os trechos para cada painel da exposição. Esta etapa da oficina também compreendeu a 
metodologia do DP, já que consistiu em procedimentos e escolhas realizados pelos pesquisadores em conjunto com as artesãs. Assim, foi criada uma matriz com três campos: foto de cada mulher guerreira, trecho da entrevista e, também, ideias e palavras da entrevista que poderiam ser materializadas em imagens a partir da mescla do artesanato.

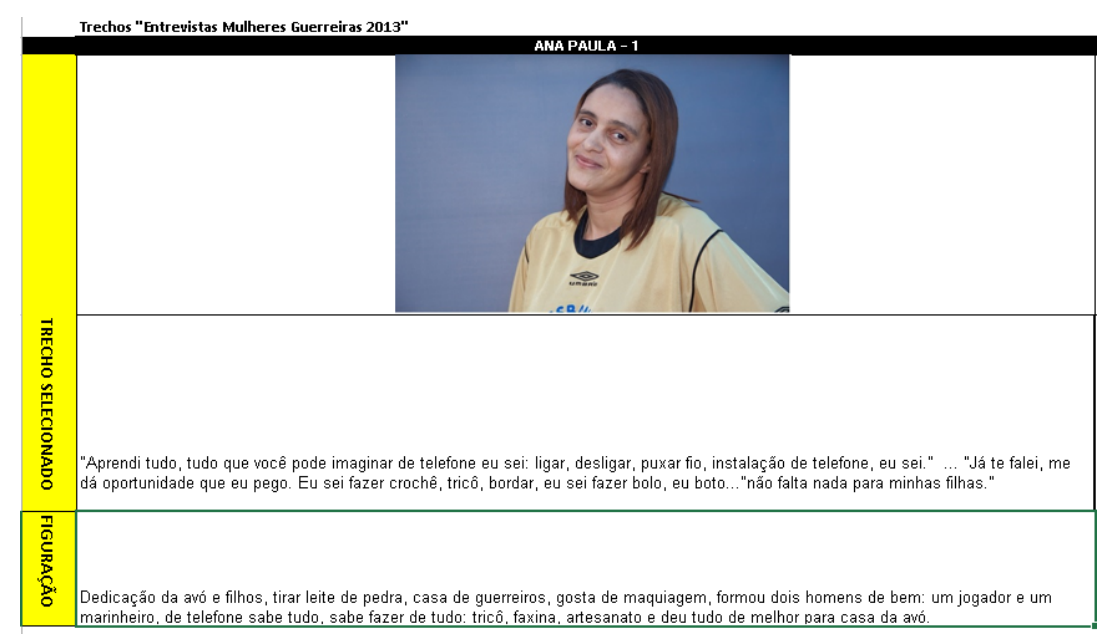

Figura 06: "Matriz dos trechos selecionados"

Elaborado pelos autores.

A entrevista da mulher guerreira selecionada Ana Paula foi utilizada como modelo para o desenvolvimento do trabalho e será utilizada neste artigo para demonstrar o processo realizado com todas outras mulheres.

$\mathrm{Na}$ entrevista, Ana Paula conta sobre sua história de vida e ressalta sobre sua profissão de técnica de telefonia, assim os pesquisadores e artesãs definiram que o trecho a seguir seria selecionado para o painel da mulher guerreira: "Aprendi tudo, tudo que você pode imaginar de telefone eu sei: ligar, desligar, puxar fio, instalação de telefone, eu sei... Já te falei, me dá oportunidade que eu pego". A partir da frase selecionada foram elencados quais elementos visuais poderiam traduzir a frase de Ana Paula.

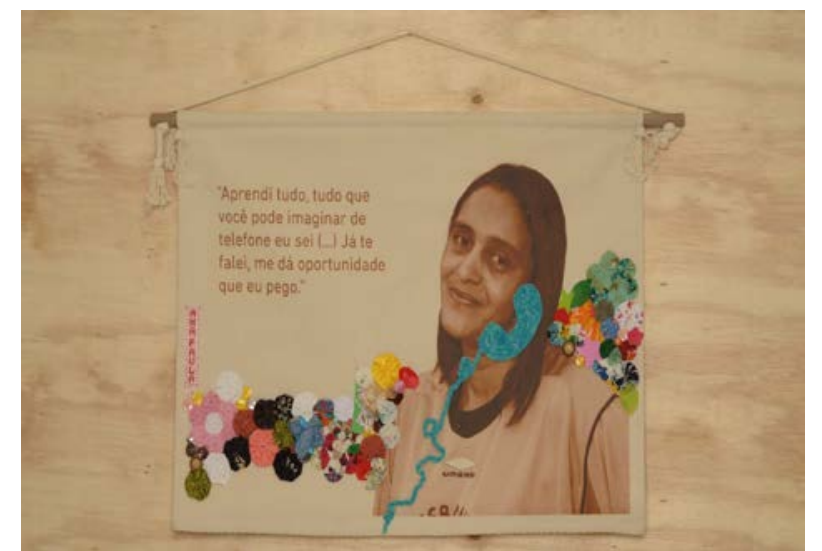

Figura 07: "painel resultado da Mulher Guerreira Ana Paula" Elaborado pelos autores. 
No painel de Ana Paula, foi utilizado o elemento figurativo do telefone e o fio já que estes se relacionam com a profissão da mulher guerreira. Os elementos abstratos, também, foram usados no painel para representar outros trechos da entrevista. A parte inferior do painel apresenta uma intervenção com a técnica artesanal de fuxico, todos acumulados, representando o conceito de cheio e, também, a habilidade de Ana Paula com o artesanato. A parte superior apresenta o vazio. Deste modo, ambos os conceitos foram trabalhados nas oficinas de capacitação da etapa $\mathbf{A}$.

$\mathrm{Na}$ etapa F: Mutirão de confecção. Nesta etapa, pesquisadores e alunos de Design da PUC-Rio auxiliaram as artesãs do MUF na intervenção dos treze painéis da exposição. Confirma-se os princípios da metodologia do design participativo que tem como característica, conforme apontado por Bianco e Damazio (2007) uma abordagem pensada em um contexto social que visa a integração do usuário e do designer. Essa relação do designer com suas habilidades e do parceiro, nesse caso as artesãs do MUF, também com suas habilidades do artesanato e experiências de vida na comunidade possibilitaram o desenvolvimento da exposição por meio da troca de saberes o que para Fabiarz e Ripper (2011) é uma construção por meio da partilha e troca de saberes.

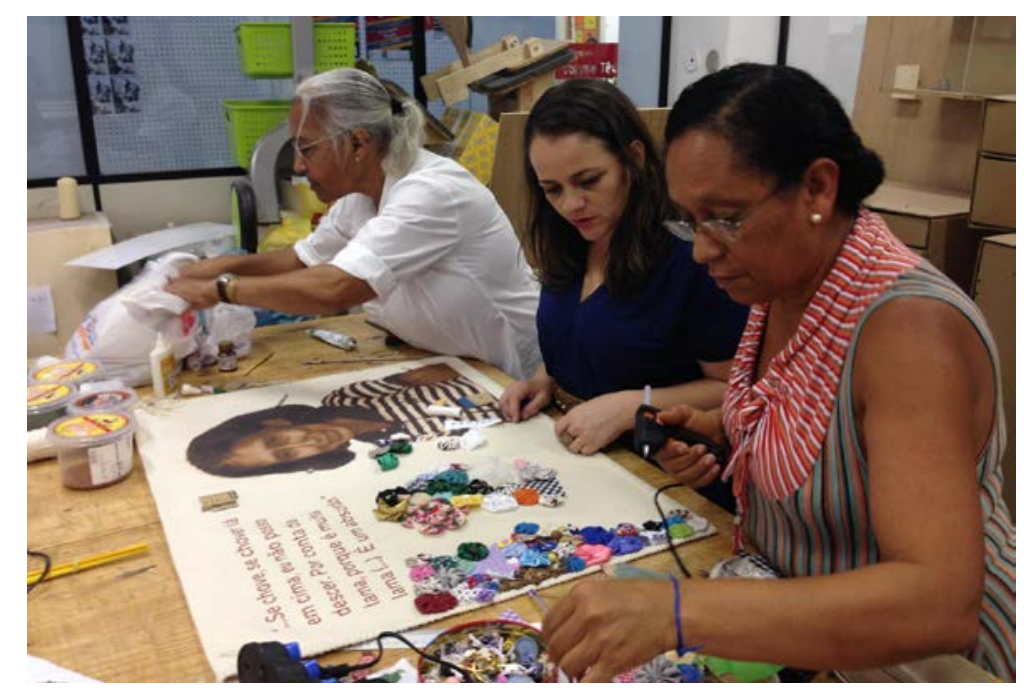

Figura 08: Artesãs com colaboradores no mutirão Elaborado pelos autores.

\subsection{Painéis Resultados}

Na página seguinte, apresentamos dois dos treze painéis criados para exposição Mulheres Guerreiras. A exposição foi lançada em 07 de março de 2015 em homenagem ao dia da mulher no morro do Cantagalo, na Zona Sul do Rio de Janeiro. A exposição encontra-se exposta na sede do MUF, também, no morro do Cantagalo. 
Painel Mulher Guerreira Derci

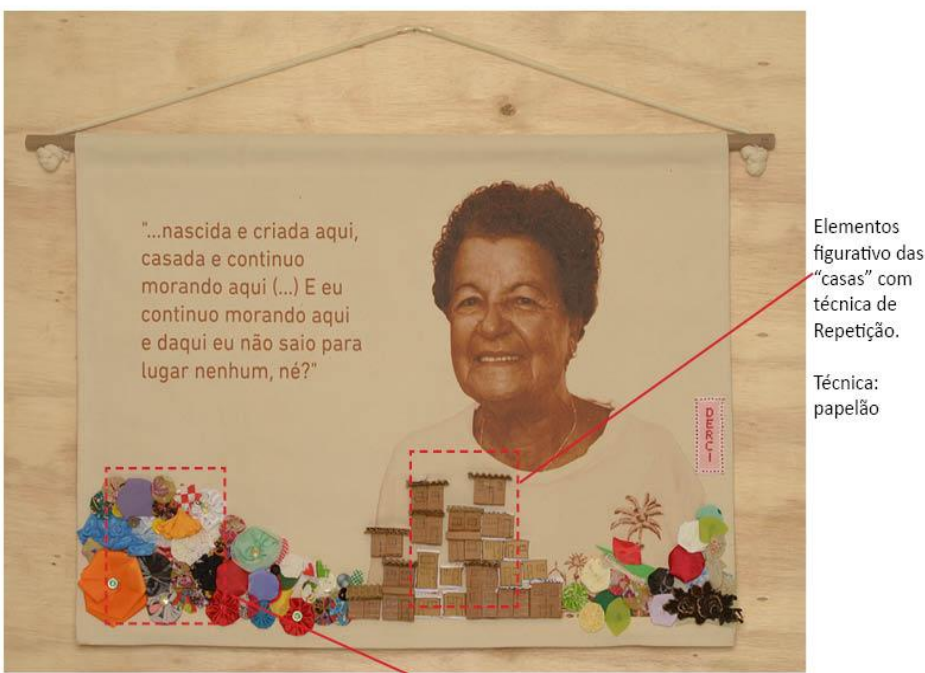

Preenchimento abstrato simplesmente de ornamentação - sem figuração.

Painel Mulher Guerreira Selm

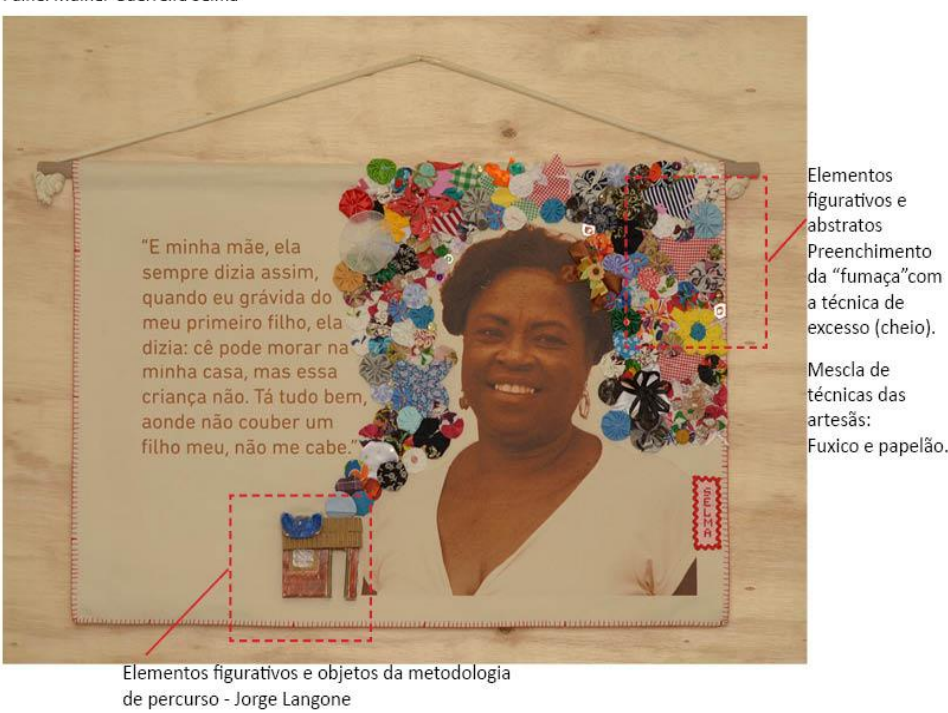

Painel Mulher Guerreira Ana Paula

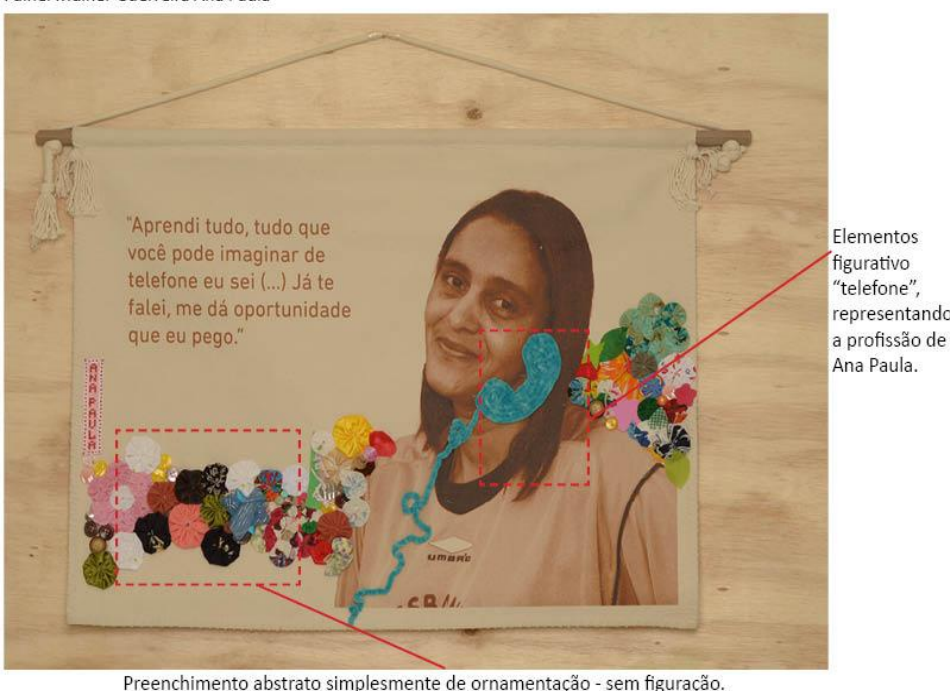

Figuras 8, 9 e 10: Mulheres Guerreiras: Derci, Selma e Ana Paula.

Elaborado pelos autores. 


\section{CONCLUSÃO}

A pesquisa possibilitou a consolidação da relação da Universidade, por meio do NIMESC com as comunidades, por meio do MUF, construindo um conhecimento em conjunto por pesquisadores e moradores sobre universo da favela e do design, apontando e registrando memória, linguagem e materialidade de um grupo de mulheres que fazem parte da história das comunidades. O resultado da exposição possibilitou o fortalecimento da identidade destas comunidades, proporcionando as mulheres homenageadas o fortalecimento da autoestima quando se veem representadas por meio de simbologias e as artesãs com suas técnicas artesanais valorizadas e aplicadas em uma exposição.

A aplicação prática de soluções de design participativo depende do comprometimento e ação de diferentes protagonistas, no qual a pesquisa e projeto em design é, apenas, uma ligação. O design tem capacidade de cooperar com seu saber para possibilitar essas iniciativas, porque sua metodologia apresenta dimensões técnicas, produtivas e sociais, essenciais para o triunfo de uma solução no mercado e para o melhor aproveitamento de matérias primas. Foi possível concluir que é possível levar o design para as comunidades menos favorecidas cujas preocupações principais não se restringem, apenas, a necessidade do comer, vestir e abrigar. A academia não é o caminho imediato para soluções dos problemas das comunidades, mas através da pesquisa participativa é possível oferecer soluções não imediatas, mas eficazes de solução de seus problemas mais prementes.

O Design vem ao encontro da pesquisa no MUF em uma metodologia participativa, dando aos moradores e aos pesquisadores a oportunidade de projetarem juntos. Reconhecemos o design como um caminho que visa solucionar problemas de nossa sociedade, tendo como meta a melhoria das condições de vida dos diferentes grupos de comunidades, colocando os indivíduos no centro das atenções do projeto, respeitando a cultura particular de cada grupo.

Podemos concluir que a participação dos moradores na construção de uma plataforma visual dos elementos sígnicos que compõe a representação da sua localidade, amplia o conhecimento desses moradores em relação aos sinais visuais de pertencimento a um determinado espaço. Essa ação propicia um maior reconhecimento e uma diferenciação em relação às outras comunidades. O Designer como cidadão deve levar em conta a legitimação dessa questão, oferecendo visibilidade, validando a importância da cultura na transformação do ser humano e na formação da identidade.

\section{REFERÊNCIAS}

ATHAYDE, Celso; MEIRELLES, Renato. Um País Chamado Favela. São Paulo: Editora Gente, 2014.

COUTINHO, S. Davison. Um olhar sobre a produção cultural na Rocinha. Rio de Janeiro, Minister, 2013.

DAL BIANCO, Bianca; DAMAZIO, Vera. Design em parceria: reflexões sobre um modo singular de projetar sob a ótica do design e emoção. 2007. Dissertação (mestrado) - 
Pontifícia Universidade Católica Do Rio De Janeiro. Programa de Pós-Graduação em Design.

COUTINHO, Davison; GAMBA JR, Nilton G. Design, Cultura Material, Artesanato e Memória no Museu de Favela do Rio de Janeiro. 2016. 182 f. Dissertação (mestrado) Pontifícia Universidade Católica do Rio de Janeiro. Programa de Pós-Graduação em Design.

FABIARZ, Jaqueline e RIPPER. In: COELHO. Luiz; WESTIN. Denise. Estudo e Prática de Metodologia em design nos cursos de pós-graduação. Rio de Janeiro: Ed. Novas Idéias, 2011.

HALBWACHS, Maurice. A Memória Coletiva. São Paulo: Centauro, 2006.

LAHUD, Michel. A vida clara. Linguagens e realidade, segundo Pasolini. São Paulo, Companhia das Letras/UNICAMP, 1993.

SANTA-ROSA, José Guilherme e MORAES, Anamaria de. Design Participativo. Técnicas de inclusão de usuários no processo ergodesign de interfaces. Rio de Janeiro, Riobooks, 2012. 